\title{
Fontes do conhecimento histórico em Educação e Educação Especial: entre a tradição e a renovação
}

\author{
Sources of historical knowledge in Education and Special Education: between \\ tradition and renewal
}

Fuentes de conocimiento histórico en Educación y Educación Especial: entre tradición y renovación

\section{Adriana Araújo Pereira Borges}

Professora doutora na Universidade Federal de Minas Gerais. Belo Horizonte, Minas Gerais, Brasil.

adriana.borges@terra.com.br

ORCID - http://orcid.org/0000-0003-0493-0099

\author{
Maria Edith Romano Siems \\ Professora doutora na Universidade Federal de Roraima, Boa Vista, Roraima, Brasil. \\ edith.romano@ufrr.br \\ ORCID - http://orcid.org/0000-0001-5527-0065
}

Recebido em 17 de agosto 2020

Aprovado em 21 de agosto de 2020

Publicado em 13 de novembro de 2020

\section{RESUMO}

O entendimento das bases históricas sobre as quais se assentam os saberes e as práticas nas quais se apoiam os profissionais atuantes nos diferentes níveis e modalidades que constituem os sistemas educativos é elemento fundamental para o avanço técnico, científico, social e cultural. A renovação das metodologias em pesquisa histórica a partir do movimento denominado como Escola dos Annales, ampliou o leque de perspectivas historiográficas de compreensão da estruturação dos variados campos de atividades humanas, oportunizando expansão e diversificação de olhares e rompendo a lógica da história como crônica de acontecimentos. $O$ artigo traz uma pesquisa exploratóriodescritiva, que busca analisar as bases teórico-metodológicas em que foram desenvolvidos os estudos históricos em Educação Especial apresentados no período de 2008 a 2018, em eventos acadêmico-científicos de destaque no campo da Educação Especial e da História da Educação em contexto brasileiro. Para tanto, foram utilizadas as seguintes categorias: o objeto de estudo/tema e área de educação especial em que se insere; o recorte temporal considerado; as fontes priorizadas, os procedimentos metodológicos de coleta e análise de dados; e os referenciais teórico-epistemológicos indicados. Os resultados indicam que a produção de pesquisas na História da Educação Especial ainda é incipiente e reflete a interdisciplinaridade do campo de conhecimento, reconhecendo que a História da Educação Especial é antes de tudo, indisciplinada.

Palavras-chave: História da Educação Especial; Educação Especial; campo interdisciplinar. 
http://dx.doi.org/10.5902/1984686X53212

\section{ABSTRACT}

Understanding the historical bases on which knowledge and practices are based on which professionals working at the different levels and modalities that constitute educational systems are established is a fundamental element for technical, scientific, social and cultural advancement. The renewal of methodologies in historical research based on the movement called Escola dos Annales, expanded the range of historiographical perspectives for understanding the structuring of the varied fields of human activities, providing opportunities for expansion and diversification of views and breaking the logic of history as a chronicle of events. The article brings an exploratory descriptive research, which seeks to analyze the theoretical and methodological bases on which the historical studies in Special Education presented in the period from 2008 to 2018 were developed, in prominent academic-scientific events in the field of Special Education and History of Education in a Brazilian context. For this, the following categories were used: the object of study / theme and the area of special education in which it is inserted; the time frame considered; the prioritized sources, the methodological procedures for data collection and analysis; and the theoretical-epistemological references indicated. The results indicate that the production of research in the History of Special Education is still incipient and reflects the interdisciplinarity of the field, recognizing that the History of Special Education is, above all, undisciplined.

Keywords: History of Special Education; Special Education; interdisciplinary field.

\section{RESUMEN}

Comprender las bases históricas en las que se basan los conocimientos y las prácticas en los que se establecen los profesionales que trabajan en los diferentes niveles y modalidades que constituyen los sistemas educativos es un elemento fundamental para el avance técnico, científico, social y cultural. La renovación de las metodologías en la investigación histórica basada en el movimiento llamado Escola dos Annales, amplió el rango de perspectivas historiográficas para comprender la estructuración de los variados campos de las actividades humanas, brindando oportunidades para la expansión y diversificación de puntos de vista y rompiendo la lógica de la historia como crónica de eventos. El artículo presenta una investigación descriptiva exploratoria, que busca analizar las bases teóricas y metodológicas sobre las cuales se desarrollaron los estudios históricos en Educación Especial presentados en el período de 2008 a 2018, en destacados eventos académico-científicos en el campo de la Educación Especial y la Historia de La educación en un contexto brasileño. Para ello, se utilizaron las siguientes categorías: el objeto de estudio / tema y el área de educación especial en la que se inserta; el plazo considerado; las fuentes priorizadas, los procedimientos metodológicos para la recolección y análisis de datos; y las referencias teórico-epistemológicas indicadas. Los resultados indican que la producción de investigación en Historia de la Educación Especial todavía es incipiente y refleja la interdisciplinariedad del campo, reconociendo que la Historia de la Educación Especial es, sobre todo, indisciplinada.

Palabras clave: Historia de la Educación Especial; Educación Especial; campo interdisciplinario. 
http://dx.doi.org/10.5902/1984686X53212

\section{Introdução}

Como situar a História da Educação Especial? Para discutir essa questão, nos baseamos primeiro, na perspectiva de Martine Ruchat (2003), que defende a ideia de que as bases da História da Educação Especial se encontram na sociologia. Depois, apresentamos a perspectiva da História da Psicologia. Por fim, as contribuições da História da Educação para o debate.

Para Ruchat (2003), a História da Educação Especial é plural, transdisciplinar, interdisciplinar, ou seja, indisciplinada, pois não se inscreve dentro de uma lógica disciplinar. Os objetos da história da educação especial pertenceriam a uma realidade construída, relativa, arbitrária, simbólica, que revela a história das classificações, noções e conceitos que pontuam a história da criança problema. Fundamentalmente, o campo da História da Educação Especial se constituiu, segundo a pesquisadora, a partir de questionamentos. Os profissionais da educação especial do pós-guerra procuravam uma filiação. Para isso, vão reconstruir a história dos pioneiros e das instituições especializadas. A história passa a ser entendida como um meio para que esse corpo profissional possa se definir melhor, examinando seu passado e salvaguardando a herança comum para as gerações futuras.

A História da Educação Especial, teria se desenvolvido a partir dos anos 1970, em torno da história de duas grandes instituições do século 19: a escola e a prisão. A prisão, instituição total e a escola, instituição desigual. De um lado, as prisões, que desde os anos 1950 são objeto da sociologia do desvio, em particular da delinquência juvenil. Por outro lado, a escola, a partir de uma corrente crítica da sociologia e da filosofia, que discutia o papel normativo da escola, sua função colonizadora das classes populares e reprodutora das classes sociais, que fez emergir uma nova categoria: a infância anormal. A pesquisadora defende que a História da Educação Especial tem sua origem na sóciohistória, na história dos atores e dos mecanismos sociais, estudados através da questão do poder e dos conflitos de interesse. Ou seja, para Ruchat (2003) a História da Educação Especial no ocidente é fortemente influenciada pela sociologia americana e francesa, pois são as ciências sociais que melhor compreendem os fenômenos da marginalidade, da delinquência, do atraso, da segregação, da vulnerabilidade e da deficiência.

No entanto, não nos parece possível negar a forte relação entre História da Educação Especial e História da Psicologia. A História da Psicologia tem sofrido transformações. Acusada de ficar restrita a uma abordagem cerimonial e pouco crítica dos personagens, 
http://dx.doi.org/10.5902/1984686X53212

ideias e escolas psicológicas, passou a se debruçar sobre o impacto dos fatores culturais, sociais e políticos da teoria e da prática da psicologia em seu desenvolvimento histórico (ARAÚJO, 2016). Outras contribuições importantes da historiografia da psicologia, dizem respeito às pesquisas realizadas sobre o diálogo entre o global e o local, a partir dos conceitos de recepção e circulação (BRANCO et al, 2016; CAMPOS; BORGES, 2014). Quanto à metodologia, Araújo defende que não existe um método a priori para fazer história da psicologia: "Ao invés disso, a abordagem metodológica deve ser derivada da natureza do assunto pesquisado e das questões levantadas pelo historiador" (ARAÚJO, 2016, p.14). $O$ autor defende também uma maior integração entre a história e a filosofia da psicologia. A História da Psicologia ainda faz fronteira com a História da Educação Especial, principalmente nas discussões sobre a inteligência e os testes (ROTA JÚNIOR; CIRINO; GUTIERREZ, 2018); em relação às biografias dos personagens, pois muitas das pessoas que se dedicaram ao campo da Educação Especial tiveram sua formação no campo da psicologia (CAMPOS, 2010) e ainda em relação às instituições, pois os consultórios médico-pedagógicos, as classes anexas aos hospitais psiquiátricos, as classes e escolas especiais (RAFANTE, 2006; CAMPOS; BORGES, 2012) interessam aos historiadores da psicologia da educação especial. As fontes da História da Psicologia e da História da Educação Especial podem ser as mesmas. Mas, o tratamento dessas fontes seria 0 mesmo?

Além da sociologia e da psicologia, a História da Educação Especial sofre outra influência. No Brasil, a História da Educação está presente como disciplina nos cursos de formação de professores. Para Carvalho (2005), esse atrelamento da disciplina a objetivos de formação de professores e pedagogos dificultou sua constituição como área de investigação historiográfica, "capaz de autodelimitar-se e de definir, a partir de sua própria prática, questões, temas e objetos" (CARVALHO, 2005, p. 34). Isso vem mudando paulatinamente, a partir das redefinições dos objetos e dos critérios de rigor científico, fortalecendo seu estatuto como campo de conhecimento historiográfico. Novos domínios vão sendo constituídos como a História das Disciplinas Escolares, História da Profissão Docente, História do Currículo, dentre outras. A problematização de objetos e procedimentos tem contribuído para o fortalecimento da História da Educação. Mas a História da Educação Especial seria um dos domínios da História da Educação? Sua filiação estaria vinculada a sociologia, tal como defende Ruchat? E como seria possível delimitar a fronteira entre a História da Psicologia e a História da Educação Especial? A 
http://dx.doi.org/10.5902/1984686X53212

análise dos trabalhos sobre História da Educação Especial apresentados em dois importantes Congressos, entre os anos de 2008-2018, permite discutir e avançar sobre essa questão.

\section{Apresentação de trabalhos de História da Educação Especial em Congressos: o que dizem os pesquisadores?}

Compreender os processos históricos de estruturação e funcionamento dos sistemas educativos, em suas variadas modalidades é, em nosso entendimento, importante para que se possa avançar socialmente no sentido da construção de uma educação de qualidade para todos. No Brasil, temos vivenciado, nas últimas três décadas, uma demanda expressiva pela oferta da Educação Especial em perspectiva inclusiva para todos os estudantes entendidos como público-alvo dessa modalidade: estudantes com deficiências, transtornos globais do desenvolvimento e altas habilidades/superdotação. Vivencia-se, entretanto, no interior das escolas e demais espaços educativos e sociais, práticas e concepções excludentes ou segregadoras, cujas raízes precisam ser melhor analisadas e compreendidas.

Neste sentido, estudos históricos no campo da Educação Especial no Brasil têm-se expandido em um movimento que pode ser observado nas apresentações de trabalhos em congressos científicos que tem por foco a Educação Especial e a História da Educação, dando indicativos relevantes dos avanços da área.

Em balanço bibliográfico publicado em 2017, Bezerra apresenta uma análise sobre a produção relativa à temática da História da Educação Especial brasileira nos Congressos Brasileiros de História da Educação, já com sinalizações relevantes quanto ao avanço recente da produção em História da Educação Especial, naquele que é um representativo congresso de história da Educação no Brasil. Nesse artigo o autor faz referência ao Congresso Brasileiro de Educação Especial - CBEE, evento de grande relevância para pesquisadores e profissionais atuantes na Educação Especial, mas que, em sua análise, "pela formação dos pesquisadores nele envolvidos" não teria "uma tradição "legítima" de trabalhos com foco nas dimensões históricas dessa modalidade de ensino" (BEZERRA, 2017, p. 3) o que geraria uma produção menos afeita às exigências da ciência histórica, guardando proximidade maior com as questões da Educação Especial.

Embora, a priori, concordemos com o autor no que tange à importância do tratamento historiográfico que, tende a ser mais presente em um espaço científico especificamente 
http://dx.doi.org/10.5902/1984686X53212

direcionado à História da Educação, identificamos que o estudo da História da Educação Especial também tem sido representativa neste espaço de discussão acadêmica que, por sua tradição e regularidade, concentra a presença e atenção de todos os que no Brasil se dedicam a estudos na área, por isso a escolha desse Congresso para análise dos trabalhos. Entendemos ainda que é relevante que se observe também se essa produção historiográfica brasileira, no campo da Educação Especial, que traz indícios de ter uma trajetória ascendente no volume e profundidade de sua produção, aparece em espaços mais amplos de divulgação da produção científica em História da Educação e, para isso, escolhemos o CIHELA - Congreso Iberoamericano de Historia de la Educación Latinoamericana como espaço de análise. A aproximação para análise dos trabalhos dos dois eventos, vai de encontro com o que sugere Bezerra (2017):

\begin{abstract}
Os estudos sobre História da Educação Especial são pouco frequentes, seja no âmbito das pesquisas gerais em História da Educação, seja no âmbito da pesquisa em Educação Especial propriamente dita, existindo certo hiato entre esses dois campos. Dessa forma, verifica-se a necessidade de maior aproximação entre ambos, com vistas a se ampliarem também as perspectivas de trabalho historiográfico em torno da Educação Especial brasileira, nos seus múltiplos aspectos, tempos, espaços e sujeitos implicados, haja vista a relevância de iniciativas como esta para a preservação da história e memória da referida modalidade educacional (BEZERRA, 2017, p. 20).
\end{abstract}

O Congresso Brasileiro de Educação Especial - CBEE foi realizado, pela primeira vez, em 2003, ano em que o Programa de Pós-graduação em Educação Especial da Universidade Federal de São Carlos - PPGEEs/UFSCar completava 25 anos de existência e a Associação Brasileira de Educação Especial - ABPEE completaria 10 anos, como um desdobramento dos "Ciclos de Estudo sobre deficiência Mental" e dos "Seminários de Pesquisa em Educação Especial" que já ocorriam na UFSCar, e que tinham como consequência publicações relevantes da área atraindo, a cada edição, um público maior de participantes (CBEE, 2008). Realizado em periodicidade bienal, em seu site de apresentação da edição de 2018 indica que "esse Congresso tem se materializado como importante espaço de debate e divulgação do conhecimento científico produzido na área da Educação Especial nacional e internacional" (CBEE, 2008, s/p).

Na programação do CBEE estão presentes simpósios, mesas redondas, minicursos e sessões de apresentação de trabalhos, no formato de comunicações orais ou pôsteres, que são distribuídos em eixos temáticos propostos pela organização do Congresso. Nas sessões de apresentação de trabalhos, temos um expressivo painel da produção nacional 
http://dx.doi.org/10.5902/1984686X53212

de pesquisa em Educação Especial que tem, tradicionalmente, a presença de pesquisadores de todas as regiões brasileiras, constituindo-se em espaço de ampla representação da produção acadêmica da área no Brasil, com trabalhos que vão de pesquisas de iniciação científica e trabalhos desenvolvidos em formações stricto sensu, a projetos de pesquisa institucionalmente reconhecidos.

Em face da representatividade deste evento e, no sentido de ampliar o conhecimento em relação à produção em História da Educação Especial brasileira, nos propusemos a realizar um inventário relativo aos textos apresentados no período de 2008 a 2018 neste Congresso.

Já a primeira edição do CIHELA, ocorreu em 1992, mesma década em que se institucionalizaram várias Sociedades Nacionais de História da Educação na América Latina. O I Congreso Iberoamericano de Docentes e Investigadores em Historia de la Educación Latinoamericana ocorreu em Bogotá, na Colômbia, marcando o início de um processo de configuração de uma comunidade ibero-americana de historiadores da educação (GALLEGO; CARO, 2014). Depois dessa edição, o congresso passou a ocorrer de dois em dois anos, com algumas exceções. De acordo com os anais do XI Congresso, o objetivo destes encontros tem sido auxiliar na compreensão das relações entre a educação, a cultura e a sociedade. Esses espaços foram se constituindo como um local de reflexão sobre os sujeitos, a educação, sua pluralidade e heterogeneidade e também, sobre as formas como a educação tem contribuído para a geração de identidades e para os processos de autonomia na América Latina. Além disso, os Congressos buscam discutir a historiografia, a análise comparada, propiciando o encontro de investigadores, a participação de jovens, a formação de grupos de investigação e de redes acadêmicas. A princípio, foi pouco representativa a presença de trabalhos sobre História da Educação Especial nos Congressos analisados. No entanto, observa-se um crescente interesse pelos estudos históricos em Educação Especial.

\section{Fundamentos teórico-metodológicos}

Em relação aos procedimentos metodológicos adotados, foi realizada uma pesquisa exploratório descritiva nos anais publicados em mídia eletrônica nos anos de 2008, 2010 e 2012 e nos acervos eletrônicos disponíveis do CBEE dos anos de 2014, 2016 e 2018, que trouxessem em seu título, resumo ou palavras-chave, referências a tratar-se de estudo de natureza histórica, no caso das edições até 2014. Nos anos de 2016 e 2018, com a 
http://dx.doi.org/10.5902/1984686X53212

existência de eixo temático específico de História da Educação Especial, nos concentramos nos trabalhos publicados nesse eixo. No caso do CIHELA, foram adotados os mesmos procedimentos, a partir da análise dos anais dos anos de 2014, 2016 e 2018. Os registros dos anos de 2009 e de 2012 não foram localizados. Os trabalhos disponibilizados correspondem, em especial, às comunicações orais e pôsteres submetidos para apresentação e, na análise dos trabalhos focamos nossa atenção em categorias que entendemos serem relevantes e que também trazem aproximação com categorias que foram consideradas no estudo de Bezerra (2017) como: o objeto de estudo/tema e área da Educação Especial em que se insere; qual o recorte temporal considerado; procedimentos metodológicos de coleta e análise de dados; fontes priorizadas e referenciais teóricoepistemológicos indicados.

A opção por determinadas perspectivas epistemológicas pressupõe a prática da reflexividade. A reflexividade requer dos pesquisadores 0 desenvolvimento de uma consciência crítica permanente com relação aos aspectos sociais que estão envolvidos no processo de produção do conhecimento em sua pesquisa (KOCH; HARRINGTON,1998). Além disso, a reflexividade envolve o uso consciente e reflexivo das teorias, bem como 0 reconhecimento de potenciais limitações (MAINARDES, 2017, p.3).

Portanto, esse artigo procura explorar e localizar quais referenciais teóricoepistemológicos têm sido utilizados pelos historiadores da Educação Especial, a partir do que pode ser considerado "pesquisa da pesquisa" (SILVA; GAMBOA, 2014). Nesse sentido, é necessário reconhecer a importância dos Congressos como meios privilegiados para a difusão científica. A apresentação de trabalhos em eventos é considerada um canal de comunicação informal, em contraposição aos canais formais (publicação de artigos em periódicos, livros, capítulos).

É importante destacar que no caso do CBEE tivemos acesso aos artigos completos. No caso do CIHELA, foram acessados os resumos dos trabalhos no ano de 2014 e os trabalhos completos dos anos de 2016 e 2018. Muitos trabalhos apresentados em Congresso são pesquisas em andamento, o que por um lado limita a análise, mas por outro lado, permite problematizar a questão da importância da utilização dos referenciais pelos pesquisadores que apresentam suas pesquisas nos congressos.

Como parâmetro de exclusão, optamos por considerar somente os textos que se referem a estudos históricos em Educação Especial no contexto brasileiro, excluindo os de Torres (2016) e Murcia e Rahme (2018) presentes no CBEE, por referirem-se a estudos realizados em Espanha e Colômbia. Da mesma forma procedemos em relação ao CIHELA. 
http://dx.doi.org/10.5902/1984686X53212

\section{A História da Educação Especial nos Congressos Brasileiros de História da Educação Especial}

Em termos numéricos, os CBEE apresentam elevado volume de comunicações de trabalhos em uma média que se aproxima dos 940 trabalhos/edição. A organização do evento dá-se em eixos com temáticas variadas e, entre os anos de 2008 e 2014, observamos que a maior presença de trabalhos com estudos históricos deu-se nos eixos temáticos que se desenvolvem no campo de estudos da Surdez/Deficiência auditiva, Produção de Conhecimentos em Educação Especial e Políticas Educacionais. Nos anos de 2016 e 2018, ocorre a inserção de um eixo temático específico de História da Educação Especial, que concentra os trabalhos produzidos neste campo e amplia também o volume de textos desta natureza.

Percentualmente, a representatividade da História da Educação Especial, no conjunto dos trabalhos é bastante limitada, mas é possível observar que a ênfase trazida com a definição de um eixo próprio, amplia esta presença.

Tabela 1 - Quantitativo de trabalhos apresentados nas seis últimas edições do CBEE

\begin{tabular}{c|c|c|c|c}
\hline EDIÇÃO & $\begin{array}{c}\text { TOTAL DE } \\
\text { TRABALHOS }\end{array}$ & $\begin{array}{c}\text { EIXOS } \\
\text { TEMÁTICOS }\end{array}$ & $\begin{array}{c}\text { TRABALHOS COM } \\
\text { VIÉS HISTÓRICO }\end{array}$ & $\%$ \\
\hline 2008 & 971 & 23 & 9 & $0,92 \%$ \\
\hline 2010 & 1177 & 24 & 7 & $0,59 \%$ \\
\hline 2012 & 900 & 24 & 11 & $1,21 \%$ \\
\hline 2014 & 885 & 26 & 9 & $1,01 \%$ \\
\hline 2016 & 913 & 28 & 22 & $2,40 \%$ \\
\hline 2018 & 791 & 28 & 16 & $2,02 \%$ \\
\hline Total & 5637 & -- & 74 & $1,31 \%$ \\
\hline
\end{tabular}

Fonte: Elaborada pelas autoras com base nos anais do CBEE (2020).

Em relação à questão do recorte temporal considerado nas pesquisas apresentadas, aspecto relevante no campo da historiografia, dos 74 trabalhos que aqui foram analisados encontramos resultados que indicam uma fragilidade expressiva neste aspecto sendo que 31 deles não definiam o recorte temporal do estudo e oito deles apresentavam indicações genéricas como "século XX", "séculos XIX a XXI", "primeiras décadas do século XX" ou "sociedades antigas, clássica e oriental". Dos restantes, cinco trazem indicativos de referirem-se a anos específicos (1936, 1988, 1988, 1987-1988 e 2007), dois reportam-se a 
http://dx.doi.org/10.5902/1984686X53212

períodos do século XIX (década de 1870 e 1840 a 1889), oito situam seus estudos entre os anos de 1900 a 1960, três indicam estudos em períodos após o ano 2000 e os demais 17 situam seus estudos entre a segunda metade do século $X X$ e primeiras duas décadas do século $X X I$.

A Educação Especial guarda em si a peculiaridade de ter, no conjunto de seu públicoalvo, uma diferenciação que se pauta em categorias, por vezes oriundas de delimitações que se aproximam do campo dos estudos médicos e psicológicos e que se distribuem entre pessoas com deficiências físicas, sensoriais ou intelectuais, Altas Habilidades/superdotação e Transtornos de Desenvolvimento hoje inseridos no conjunto de Transtornos do Espectro do Autismo- TEA. Nos estudos históricos que analisamos há uma distribuição em que prevalecem estudos do campo da Surdez/Deficiência auditiva (14) e Cegueira/Deficiência Visual (10) fator que entendemos ter correlação direta com o fato de serem estas as áreas em que temos a mais antiga estruturação de serviços, ainda no período do Império, dos Imperiais Institutos de Educação dos "Surdos-mudos" e dos Cegos, atuais INES e IBC. Em relação a outras deficiências, encontramos um estudo relativo a deficiências físicas (um), Intelectual (três) e sem definição específica (um). Além desses, encontramos três estudos referentes ao conceito de Altas Habilidades/Superdotação e dois relativos a conceitos ligados aos transtornos do desenvolvimento. Neste sentido, encontramos aí uma forte proximidade com estudos do campo da História da Psicologia e da delimitação de conceitos de natureza eminentemente psicológica como os de inteligência, por exemplo.

Os aspectos metodológicos da pesquisa em ciência histórica, relativo ao uso de fontes, metodologias próprias e referenciais bibliográficos, foi um aspecto no qual encontramos muitos elementos de compreensão em relação ao aspecto processual que a área da História da Educação Especial vem apresentando. Neste sentido, como já havia sido sinalizado por Bezerra (2017) há fragilidades como, por exemplo, considerar determinada pesquisa como do campo da História da Educação, mas em sua descrição metodológica referir-se apenas a "pesquisa qualitativa" em sentido genérico. São frequentes, ainda, referências a "estudos de caso", "análise de conteúdo" e "análise documental". Entretanto, em um olhar mais aprofundado nas duas últimas edições (2016 e 2018), quando já havia um eixo próprio para a História da Educação Especial, encontramos avanços relevantes em relação aos procedimentos de pesquisa, rompendo com falas genéricas que aparecem nos estudos de 2008 a 2012 e que tratam de "método histórico", 
"retomada histórica", "natureza histórica" ou "resgate histórico", muito presentes junto com a ideia de apresentar a pesquisa como qualitativa.

Emergem, entretanto, no conjunto dos textos analisados uma presença de temáticas cuja abordagem aproxima-se de maneira mais direta à tradição dos estudos históricos em educação, representando estes, pouco menos de 50\% dos trabalhos. Destes, destacamos na tabela abaixo:

Tabela 2 - Quantitativo de trabalhos divididos por temas - CBEE

\begin{tabular}{c|c}
\hline TEMAS & $\begin{array}{c}\text { QUANTIDADE DE } \\
\text { TRABALHOS }\end{array}$ \\
\hline História das Políticas Públicas em Educação Especial. & 13 \\
\hline História de Intelectuais do campo da Educação Especial & 6 \\
\hline História da Educação Especial em Localidades Específicas & 5 \\
\hline História das Práticas em Educação Especial & 4 \\
\hline História de movimentos sociais de pessoas com deficiência & 3 \\
\hline História da psicologia em intersecção com a Educação Especial & 1 \\
\hline História das práticas em Educação Especial & 4 \\
\hline TOTAL & 36 \\
\hline
\end{tabular}

Fonte: Elaborado pelas autoras, com base nos anais do CBEE (2020).

No tocante ao uso das fontes, na tabela a seguir, apresentamos as fontes indicadas, seja nos resumos, seja no interior dos trabalhos, destacando que, vários trabalhos associam um conjunto diversificado de fontes.

Tabela 3 - Quantitativo das fontes de pesquisa - CBEE

\begin{tabular}{c|c|c|c|c|c|c|c}
\hline FONTES & $\mathbf{2 0 0 8}$ & $\mathbf{2 0 1 0}$ & $\mathbf{2 0 1 2}$ & $\mathbf{2 0 1 4}$ & $\mathbf{2 0 1 6}$ & $\mathbf{2 0 1 8}$ & Totais \\
\hline Documentos & 4 & 1 & 6 & 3 & 11 & 13 & 38 \\
\hline Referenciais bibliográficos & 4 & 4 & 5 & 4 & 12 & 8 & 37 \\
\hline Entrevistas & 21 & 1 & 1 & 5 & 6 & 3 & 37 \\
\hline Mídia & 2 & -- & -- & -- & 1 & 3 & 06 \\
\hline Relatos/narrativas & -- & 1 & 2 & 1 & 2 & -- & 6 \\
\hline Exão indicam fonte & -- & 2 & 1 & -- & -- & -- & 3 \\
\hline Exclusivamente entrevista & 1 & 1 & -- & 4 & 2 & & 08 \\
Referenciais bibliográficos & 3 & 3 & 1 & 1 & 4 & 3 & 15 \\
\hline
\end{tabular}

Fonte: Elaborado pelas autoras com base nos anais do CBEE (2020). 
Destacamos aqui que apenas oito estudos utilizam a denominação "fontes primárias" e dois deles "fontes secundárias", terminologia própria dos estudos históricos. Das metodologias de pesquisa que apresentam fidelidade aos parâmetros e aos referenciais teóricos considerados no âmbito da ciência histórica vamos encontrar uma prevalência relevante de Histórias de vida (12), em sua maior parte de sujeitos com deficiência ou intelectuais da área e de Revisões bibliográficas (oito), na forma de artigos que vão nutrirse especificamente de textos históricos já produzidos por outros autores para compreender algum campo específico. Além desses dois formatos de pesquisa, encontramos uma ampla variedade de referenciais teórico-metodológicos que descrevemos a seguir:

Tabela 4 - Quantitativo dos referenciais teórico-metodológicos - CBEE

\begin{tabular}{c|c}
\hline REFERENCIAIS TEÓRICO- METODOLóGICOS & $\begin{array}{c}\text { QUANTIDADE DE } \\
\text { TRABALHOS }\end{array}$ \\
\hline História Social e Cultural & 6 \\
\hline Estudos sobre cultura e identidade surda & 2 \\
\hline História Oral & 2 \\
\hline História do Livro e da Leitura (Chartier) & 1 \\
\hline História Vista de Baixo (EP Thompson) & 1 \\
\hline Estudos Culturais & 1 \\
\hline Estudos da linguagem & 1 \\
\hline Autobiografia & 1 \\
\hline Cultura material escolar & 1 \\
\hline Pesquisa histórico-social & 19 \\
\hline TOTAL & 3
\end{tabular}

Fonte: Elaborado pelas autoras com base nos anais do CBEE (2020)

Observamos ainda, em nossa revisão, quais seriam os autores ou matrizes de pensamento referenciadas pelos pesquisadores para a fundamentação de suas análises e, dentre esses, não quantificando ou trazendo parâmetros exclusivos que seriam de difícil verificação, encontramos estudos que partem da psicologia histórico-cultural, sóciohistórica ou da pedagogia histórico-crítica; posicionamentos claros em referenciais do materialismo histórico-dialético; estudos sócio culturais da infância; teoria crítica; referenciais gramscianos; referencial teórico da resiliência e biopoder, como campos de pensamento que, em muitos momentos, são utilizados para fundamentar as análises sobre os achados dos pesquisadores e suas reflexões sobre eles. 
http://dx.doi.org/10.5902/1984686X53212

Percebemos, a partir desse levantamento que, embora as pesquisas apresentadas tragam a proposição de inserir-se nessa interface entre a historiografia e a educação especial, o fato de serem desenvolvidas por pesquisadores que originalmente vem do campo da psicologia ou da educação especial ainda tem um percurso a construir no sentido de trazerem critérios mais fiéis aos aspectos teórico-metodológicos da História e da História da Educação. A produção que até aqui encontramos, vem se ampliando e aprofundando em termos qualitativo, o que contribui significativamente para os avanços da área.

\section{A História da Educação Especial nos Congressos Iberoamericanos de História da Educação Latinoamericana}

Nessa seção, analisamos os artigos da História da Educação Especial apresentados nos Congressos de 2014, 2016 e 2018. Os anais dos anos de 2009 e 2012, realizados respectivamente no Rio de Janeiro e em Salamanca, não se encontram digitalizados para consulta, por isso os resumos desses anos não foram analisados.

No Congresso de 2014 ocorrido em Toluca, no México, foram localizados somente 4 artigos do campo da Educação Especial no Brasil, em um total de 778 trabalhos publicados nos anais. O tema do Congresso foi Sujetos, poder y disputas por la educación. Em 2016, o Congresso foi cidade de Medellín, com o tema "História das instituições, práticas e saber pedagógico na Iberoamérica". Embora essa temática geral fosse propícia para a apresentação de trabalhos do campo da Educação Especial, de um total de 349 resumos expandidos, foram encontrados somente dois trabalhos sobre a História da Educação Especial no Brasil. Já no Congresso de 2018, realizado em Montevidéu, no Uruguai, de um total de 443 resumos, foram localizados sete resumos. O tema escolhido foi Política, espacio público y disputas en la historia de la educación en América Latina. A 100 años de la reforma de Córdoba. Sobre a participação de brasileiros no CIHELA, é possível tecer alguns comentários. Embora tímida, a participação de pesquisadores da História da Educação Especial no último Congresso realizado em 2018, contou com a apresentação de sete trabalhos. O envolvimento de novas gerações de pesquisadores do campo da Educação Especial que se interessam pela História necessita ser incentivado, pois existe um potencial de pesquisas a serem realizadas. É possível avaliar essa potencialidade através dos temas apresentados nos três Congressos. Foram 13 os trabalhos localizados, divididos pelas seguintes temáticas: 
http://dx.doi.org/10.5902/1984686X53212

Tabela 5 - Quantitativo dos Temas - CIHELA

\begin{tabular}{c|c}
\hline TEMAS & QUANTIDADE DE TRABALHOS \\
\hline $\begin{array}{c}\text { História de Instituições e História das Políticas Públicas em } \\
\text { Educação Especial }\end{array}$ & 2 \\
\hline História de Intelectuais do campo da Educação Especial & 2 \\
\hline História de Instituições & 2 \\
\hline História das Práticas em Educação Especial & 2 \\
\hline História da Educação Especial em Localidades específicas & 1 \\
\hline História das Classes Hospitalares, & 1 \\
\hline História de Instituições e Classes Hospitalares & 1 \\
\hline História de Instituições e Práticas & 1 \\
\hline História das Políticas Públicas em Educação Especial. & 13 \\
\hline TOTAL & 1 \\
\hline
\end{tabular}

Fonte: Elaborado pelas autoras com base nos anais do CIHELA (2020).

Importante destacar nessa análise que, dentre os temas apresentados, nenhum deles teve a perspectiva da comparação entre os países da América Latina. A participação em eventos faz com que os pesquisadores passem a integrar:

os "colégios invisíveis" - conceito formulado por Price (1961) e ampliado por Crane (1972) - constituindo o que hoje se conhece pela denominação por "redes de colaboração científica". O que se observa durante sua realização é a troca de experiências e conhecimento entre os pares pesquisadores e seus demais colegas, que são os autores e coautores dos trabalhos apresentados (HAYASHI, GUIMARÃES, 2016, p.162).

Ou seja, ainda se faz necessário estabelecer uma rede cooperativa entre os pesquisadores da região, para que se possa explorar aspectos ainda desconhecidos das similaridades ou dissonâncias entre a constituição do campo da Educação Especial no Brasil e nos outros países latinos.

Outro aspecto importante remete ao que já tinha sido apontado por Ruchat (2003): a História da Educação Especial é "indisciplinada", pois não se inscreve dentro de uma lógica disciplinar. Assim, é possível levantar a história de uma instituição, mas, muitas vezes, as instituições e as práticas nela desenvolvidas estão imbricadas. O mesmo em relação às políticas de Educação Especial. É possível analisar as políticas, mas essas políticas de Educação Especial, podem se relacionar com as instituições ou as práticas, fazendo com 
http://dx.doi.org/10.5902/1984686X53212

que o pesquisador acabe por estabelecer as relações históricas entre as modalidades possíveis.

Quanto ao recorte temporal, sete dos artigos tiveram um recorte temporal que se iniciou ou finalizou próximo aos anos 1960. Outros dois trabalhos focalizaram os anos 1970, sendo que um deles avançou até o final dos anos 1990. Um dos artigos apresentou um recorte demasiado longo (1889 - 2005), mas trata-se de um trabalho eminentemente bibliográfico. Outro trabalho indicou o século 19. Dois trabalhos focam em uma história recente, a partir dos anos 2000.

Sobre as fontes, foi possível observar que em alguns trabalhos, as fontes não são únicas, podendo ocorrer concomitantemente duas ou três fontes diferentes, como por exemplo, documentos (fontes primárias), bibliografia geral (fontes secundárias) e depoimentos. Nem sempre fica claro, a partir da leitura de resumos, que tipo de documentos são consultados. Um outro diferencial encontrado em dois dos resumos foi a utilização da iconografia como fonte. Dos 13 resumos, oito utilizam documentos. No entanto, é importante considerar que, a partir da Escola dos Annales, a noção de documento se amplia:

\begin{abstract}
A história faz-se com documentos escritos, quando existem. Mas pode fazerse, deve fazer-se sem documentos escritos, quando não existem. Com tudo o que a habilidade do historiador Ihe permite utilizar para fabricar o seu mel, na falta das flores habituais. Logo, com palavras. Signos. Paisagens e telhas. Com as formas do campo e das ervas daninhas. Com os eclipses da lua e a atrelagem dos cavalos de tiro. Com os exames de pedra feitos pelos geólogos e com as análises de metais feitas pelos químicos. Numa palavra com tudo o que, pertencendo ao homem, depende do homem, serve o homem, exprime o homem, demonstra a presença, a atividade, os gostos e as maneiras de ser do homem" (LE GOFF, 2016, p. 490).
\end{abstract}

Essa ampliação da noção de documento contribui para que a história possa ser questionada. Ou seja, é necessário ampliar a noção de documento, entendendo que este não é simplesmente uma coisa do passado, mas que foi fabricado pela sociedade, portanto, demonstra as relações de força dos que detinham o poder. É necessário "questionar" o documento. Esse exercício ainda necessita ser praticado por aqueles que tem procurado trabalhar com a História da Educação Especial. Descrever o documento é diferente de questionar o documento. Além das fontes documentais, os autores recorreram às entrevistas, pesquisas bibliográficas e relatos ou narrativas. 
http://dx.doi.org/10.5902/1984686X53212

Tabela 6 - Quantitativo dos tipos de fontes de pesquisa - CIHELA

\begin{tabular}{|c|c|c|c|}
\hline FONTES & $\mathbf{2 0 1 4}$ & $\mathbf{2 0 1 6}$ & $\mathbf{2 0 1 8}$ \\
\hline Documentos & 2 & 1 & 5 \\
\hline Referenciais bibliográficos & 2 & -- & 4 \\
\hline Entrevistas & 1 & -- & 4 \\
\hline Mídia & -- & -- & -- \\
\hline Relatos/narrativas & 1 & 1 & -- \\
\hline $\begin{array}{c}\text { Exclusivamente referenciais } \\
\text { Bibliográficos }\end{array}$ & 1 & -- & - \\
\hline Iconografia & -- & -- & 2 \\
\hline
\end{tabular}

Fonte: Elaborado pelas autoras com base nos anais do CIHELA (2020).

A utilização das entrevistas como fonte das pesquisas é um dado interessante. É possível ainda recorrer à algumas das personagens pioneiras na Educação Especial do Brasil para que descrevam suas experiências. A história oral serviu de base para a análise de entrevistas empreendidas por três dos autores consultados.

Quanto aos procedimentos metodológicos, os autores recorreram na maior parte das vezes a mais de uma opção, corroborando com a análise empreendida por Bezerra dos artigos dos Congressos de História da Educação no Brasil. Segundo ele, foi difícil realizar o levantamento dos procedimentos metodológicos, pois "nem todos os autores classificam ou explicitam seus procedimentos ou, ainda, como esperado, recorrem a mais de um deles, em busca de vários dados e fontes para fundamentar suas pesquisas" (BEZERRA, 2017, p.18). Esse dado justifica os números encontrados na tabela abaixo. Foi comum a triangulação de fontes: documentos, entrevistas e pesquisa bibliográfica.

Tabela 7 - Quantitativo dos procedimentos metodológicos - CHIELA

\begin{tabular}{c|c}
\hline PROCEDIMENTOS METODOLÓGICOS & QUANTIDADE DE TRABALHO \\
\hline Análise de depoimentos autobiográficos & 2 \\
\hline Pesquisa bibliográfica & 7 \\
\hline Pesquisa documental & 8 \\
\hline Entrevistas & 22 \\
\hline TOTAL & 2 \\
\hline
\end{tabular}

Fonte: Elaborado pelas autoras com base nos anais do CIHELA (2020).

Sobre os referenciais teóricos utilizados, tanto no CBEE quanto no CIHELA, a maior parte dos autores parece desconhecer a necessidade de deixar claro as matrizes 
http://dx.doi.org/10.5902/1984686X53212

epistemológicas que utilizam. De qualquer forma, é necessário lembrar que os trabalhos históricos utilizam referenciais do próprio campo. História da Educação, Historiografia, História Cultural, História "vista de baixo", História das Instituições, História da Infância, foram citadas. Também foram identificados autores de referência para a análise de políticas públicas e matrizes mais elaboradas, como o materialismo dialético. Concordamos com Ruchat, quando afirma que a historiografia da Educação Especial não é fácil de realizar. De um lado, pela sua realidade institucional, seu reconhecimento universitário enquanto campo e disciplina, o reconhecimento do estatuto científico dos seus trabalhos, o estatuto de campo interdisciplinar na universidade e, de outra parte, a realidade intelectual, ou a instabilidade de um corpo de objetos, a construção social de seus objetos, o reconhecimento de sua interdisciplinaridade ou como prefere Ruchat, a História da Educação Especial é "indisciplinada". Esse caráter diferenciado do campo pode justificar a dificuldade de alinhar as pesquisas em História da Educação Especial a matrizes epistemológicas. No entanto, a própria Ruchat reconhece a importância de que os pesquisadores percebam a filiação às ciências sociais e humanas. As fronteiras com a sociologia, a linguística, a filosofia, a antropologia e acrescentamos, à psicologia são outros aspectos que chamam a atenção. De certa forma, esse campo cruza muitos outros, no entanto, é um campo específico, mesmo com essa diversidade.

\section{CBEE e CIHELA}

A análise dos trabalhos sobre História da Educação Especial dos dois Congressos aponta para um campo em construção, com toda sua potencialidade. A maior quantidade de trabalhos apresentados no CBEE demonstra a importância desse Congresso para o campo da Educação Especial. A média de 940 trabalhos por edição é muito significativa e maior do que o número de trabalhos apresentados no CIHELA. Ao mesmo tempo, é necessário refletir sobre as dificuldades dos pesquisadores se deslocarem para fora do país para apresentarem trabalhos. Portanto, as diferenças numéricas na participação de pesquisadores nos dois Congressos, pode ser justificada por essas duas constatações.

As categorias avaliadas demonstraram a necessidade de maiores reflexões dos pesquisadores da História da Educação Especial sobre a descrição do uso de fontes, procedimentos e, principalmente, referenciais teóricos. Além disso, é possível construir e ampliar os referenciais a partir de esforços conjuntos de pesquisa, que façam o campo avançar, evitando assim, uma repetição ad eternum da mesma História da Educação 
http://dx.doi.org/10.5902/1984686X53212

Especial brasileira, como é possível notar em diversas dissertações e teses que, mesmo não sendo históricas, se utilizam desses referenciais para compor a escrita acadêmica.

A análise também permitiu divergir de um ponto colocado no artigo apresentado por Bezerra (2017). Segundo ele

...não se pode alijar da História da Educação - e, consequentemente, da prática historiográfica a ela dedicada - a Educação Especial, parte constitutiva daquela, com seus agentes, objetos, público-alvo, tensões, (con)formações, estratégias, táticas e relações de saber/ poder característicos desse último campo. (BEZERRA, 2017, p. 21)

A quantidade crescente de trabalhos históricos apresentados no CBEE demonstra a riqueza desse campo de conhecimento. Cada vez mais, trabalhos históricos são apresentados nesse Congresso. Portanto, a História da Educação Especial não pode ser considerada como constitutiva da História da Educação. Como dito anteriormente, a História da Educação Especial faz fronteira, principalmente com a História da Educação, mas também com a História da Psicologia e de outras disciplinas. A ampla variedade de artigos apresentados, a riqueza de seus objetos e fontes, nos permite concordar com Ruchat - a História da Educação Especial é indisciplinada. Não faz parte de um campo único, sendo ela mesma "um espaço crítico da educação especial, de seus discursos e de sua prática" (RUCHAT, 2003, p.165).

\section{Conclusão}

A interdisciplinaridade do campo de conhecimento da Educação Especial pode ser evidenciada no levantamento dos estudos históricos realizados no CBEE e no CIHELA, a partir de 2008. Estudos sobre os personagens da Educação Especial, suas instituições, políticas e práticas contribuem para o entendimento do lugar dessa modalidade no sistema educacional brasileiro. No entanto, ainda é necessário estimular a realização das pesquisas históricas nesse campo do conhecimento, principalmente aquelas que possam relacionar a constituição do campo da Educação Especial no Brasil com sua constituição em outros países da América Latina.

Os profissionais que trabalham com Educação Especial tendem a realizar pesquisas práticas, colocando um problema e propondo a pesquisa a fim de solucioná-lo. Dessa forma, a história acaba ocupando um lugar marginal, como se a realização da pesquisa histórica não tivesse uma finalidade. Mas Ruchat (2003) nos lembra que a História da Educação Especial é feita de paradoxos: educar e punir, proteger e disciplinar, controlar e 
http://dx.doi.org/10.5902/1984686X53212

conhecer, integrar socialmente e excluir individualmente, especificar e generalizar. Ao mesmo tempo, percebemos como a história é feita de continuidades e rupturas, que trazem consequências para várias gerações. Os estudos em História da Educação Especial permitem recuperar o passado para que possamos aprender com ele. Dessa forma, as pesquisas apresentadas nos Congressos são um importante material para que o campo de conhecimento da Educação Especial possa se consolidar cada vez mais.

\section{Referências}

ARAÚJO, Saulo de Freitas. A integração entre a História da Ciência e a Filosofia da Ciência:implicações metodológicas para a Historiografia da Psicologia. In: ASSIS, Raquel Martins; PERES, Sávio Passafaro. (Orgs.). História da Psicologia: tendências contemporâneas. Belo Horizonte: Ed. Artesã, 2016. p. 13-30.

BEZERRA, Giovani Ferreira; FURTADO, Alessandra Cristina. A produção sobre história da educação especial nos Congressos Brasileiros de História da Educação (CBHEs): um lugar em construção. Educ. rev., Belo Horizonte, v. 33, 156559, 2017 . Disponível em http://www.scielo.br/scielo.php?script=sci_arttext\&pid=S010246982017000100122\&lng=en\&nrm=iso. Acesso em 13 Aug. 2020. Epub July 13, 2017. https://doi.org/10.1590/0102-4698156559

BRANCO, Paulo Coelho Castelo et al. Recepção e circulação de objetos psicológicos: implicações para pesquisas em História da Psicologia. In: ASSIS, Raquel Martins; PERES, Sávio Passafaro. (Orgs.). História da Psicologia: tendências contemporâneas. Belo Horizonte: Ed. Artesã, 2016. p. 31-50.

CAMPOS, Regina Helena de Freitas ; BORGES, Adriana Araújo Pereira.De Genève à Belo Horizonte, une histoire croisée: circulation, réception et réinterprétation d'un modèle européen des classes spéciales au Brésil des années 1930. Paedagogica Historica (Imprimé), v. 50, 2014, p. 195-212.

CAMPOS, Regina Helena de Freitas ; BORGES, Adriana Araújo Pereira. La confluence des pratiques médicales et pédagogiques dans la construction de la psychologie appliquée au Brésil : l'exemple du Cabinet médico-pédagogique de la Société Pestalozzi de Minas Gerais (1932-1942). Interamerican Journal of Psychology, 2012. v. 46, p. 123-134.

CAMPOS, Regina Helena de Freitas. Helena Antipoff. Coleção Educadores MEC. Recife: Fundação Joaquim Nabuco, Editora Massangana, 2010.

CARVALHO, Marta Maria Chagas. Considerações sobre o Ensino da História da Educação no Brasil. In. GATTI JR, Décio; INÁCIO FILHO, Geraldo (Orgs.). História da Educação em Perspectiva ensino, pesquisa, produção e novas investigações. Campinas, SP: Autores Associados; Uberlândia, MG: EDUFU,2005, p. 33-46. 
CBEE, Congresso Brasileiro de Educação Especial . 3ª edição. Apresentação.2008. Disponível em http://www.cbee3.ufscar.br/apresentacao.php. Acesso em 13 de agosto de 2020.

GALLEGO, Alejandro Álvares; CARO, Maria Alejandra Taborda. La Historia de los Saberes Escolares: nuevas miradas a la Historia de la Educación en América Latina. In: ARATA, Nicolás; SOUTHWELL, Myriam (Org.). Ideas en la educación latinoamericana: Un balance historiográfico. Buenos Aires: Unipe Editorial Universitária, 2014. p.163-180.

HAYASHI, Maria Cristina Piumbatto Inocentini.; GUIMARÃES, Vera Aparecida Lui. A comunicação da ciência em eventos científicos na visão de pesquisadores. Revista Em Questão, v. 22, n. 3, p. 161-183, 2016.

LE GOFF, Jacques. História e Memória. 7. ed. Revista. Campinas: Editora da Unicamp, 2016.

MAINARDES, Jefferson. A PESQUISA SOBRE POLÍTICA EDUCACIONAL NO BRASIL: ANÁLISE DE ASPECTOS TEÓRICO-EPISTEMOLÓGICOS. Educ. rev., Belo Horizonte, v. 33, e173480, 2017. Disponível em

http://www.scielo.br/scielo.php?script=sci_arttext\&pid=S0102-

46982017000100156\&lng=pt\&nrm=iso. acessos em 10 jul. 2020. Epub 15-Jan-2018. https://doi.org/10.1590/0102-4698173480.

MURCIA, Yuri Esmeralda Pardo e RAHME, Mônica Maria Farid. Erase una vez y podría volver a ser... educación especial en Colombia. $n$ : ANAIS DO 8 CONGRESSO BRASILEIRO DE EDUCAÇÃO ESPECIAL , 2018, São Carlos. Anais eletrônicos... Campinas, Galoá, 2018. Disponível em: https://proceedings.science/cbee/cbee2018/papers/erase-una-vez-y-podria-volver-a-ser----educacion-especial-en-colombia. Acesso em: 20 jul. 2020.

ROTA JR., César; CIRINO, Sérgio Dias; GUTIERREZ, Laurent . Recepção/circulação dos testes de inteligência no Brasil: um recorte histórico (1920-1930). REVISTA DE PSICOLOGÍA, 2018, v. 27, p. 1-15.

RAFANTE, Heulália Charalo.; Lopes, Roseli Esquerdo. HELENA ANTIPOFF E O ENSINO NA CAPITAL MINEIRA: A Fazenda do Rosário e a Educação pelo Trabalho dos Meninos "Excepcionais" de 1940 a 1948. (Dissertação) Mestrado em Educação, Faculdade de Educação, Universidade de São Carlos, 2006.

RUCHAT, Martine. Histoire de l'éducation spéciale : une spécificité plurielle. In: CHATELANAT, Gisela; PELGRIMS, Greta (Éds.). Education et enseignement spécialisés: ruptures et intégrations. Bruxelles: De Boeck, 2003. p. 155-169

SILVA, Régis Henrique dos Reis; GAMBOA, Sílvio Áncizar Sánchez. Do esquema paradigmático à matriz epistemológica: sistematizando novos níveis de análise. Educ. Temat. Digit. Campinas, jan./abr., 2014.,v.16, n.1, p.48-66

TORRES, Leslie Freitas de. La Educacion Especial Gallega: el colégio de sordomudos y de ciegos de Santiago de Compostela. In: ANAIS DO 7ํㅡㄴ CONGRESSO BRASILEIRO DE EDUCAçãO ESPECIAL , 2016, São Carlos. Anais eletrônicos... Campinas, Galoá, 2016. 


\section{Apêndice A}

\begin{tabular}{|c|c|}
\hline \multicolumn{2}{|c|}{ Congresso Brasileiro de Educação Especial } \\
\hline \multicolumn{2}{|c|}{2008} \\
\hline Título & Autores \\
\hline $\begin{array}{l}\text { Conceito de deficiência mental no século XX: } \\
\text { construção e a (des) construção do conceito } \\
\text { com ênfase patológica }\end{array}$ & Eray Proença Muniz \\
\hline $\begin{array}{l}\text { Um estudo histórico da associação de pais e } \\
\text { amigos do deficiente auditivo de Sergipe (1970 } \\
\text { - 2000) }\end{array}$ & $\begin{array}{l}\text { Renata Beatriz de Souza Prado } \\
\text { Fabíola Rosas Sales }\end{array}$ \\
\hline A condição dos surdos nos séculos XIX E XX & Verônica dos Reis Mariano Souza \\
\hline $\begin{array}{lrr}\text { O processo de } & \text { identificação } & \text { histórico de } \\
\text { estudantes } & \text { com } & \text { Altas }\end{array}$ & $\begin{array}{l}\text { Cláucia Honnef ; Bárbara Martins de } \\
\text { Lima Delpretto; Karine Sefrin Speroni }\end{array}$ \\
\hline $\begin{array}{l}\text { Habilidades/Superdotação: Vicissitudes e } \\
\text { desafios }\end{array}$ & $\begin{array}{l}\text {; Soraia Napoleão Freitas; Miriam } \\
\text { Oliveira Maciel }\end{array}$ \\
\hline $\begin{array}{l}\text { História e educação de um menino com Altas } \\
\text { Habilidades: mitos e representações culturais } \\
\text { sobre este caso }\end{array}$ & $\begin{array}{l}\text { Tatiane Negrini; Soraia Napoleão } \\
\text { Freitas }\end{array}$ \\
\hline $\begin{array}{l}\text { Os primórdios da educação especial no Brasil e } \\
\text { a atuação da psicóloga Helena Antipoff }\end{array}$ & $\begin{array}{l}\text { Heulalia Charalo Rafante } \\
\text { Roseli Esquerdo Lopes }\end{array}$ \\
\hline $\begin{array}{l}\text { Políticas públicas para a alfabetização de } \\
\text { surdos: um diálogo com o século XIX }\end{array}$ & Maria P. S. Assunção \\
\hline $\begin{array}{l}\text { Exclusão, segregação e inclusão: a história da } \\
\text { educação especial/inclusiva dos deficientes } \\
\text { visuais }\end{array}$ & Diones Carlos de Souza Almeida \\
\hline $\begin{array}{l}\text { Identidade e deficiência: história de vida de } \\
\text { uma pessoa surda }\end{array}$ & José Anchieta de Oliveira Bentes \\
\hline \multicolumn{2}{|l|}{2010} \\
\hline $\begin{array}{l}\text { Rumo aos } 50 \text { anos de educação especial no } \\
\text { Brasil: que caminhos trilhamos e que legado } \\
\text { deixamos? }\end{array}$ & Álvaro José de Oliveira \\
\hline $\begin{array}{l}\text { A Escola Nova e a constituição da demanda } \\
\text { pela educação dos "excepcionais" nas } \\
\text { primeiras décadas do século XX. }\end{array}$ & $\begin{array}{l}\text { Heulalia Charalo Rafante } \\
\text { Roseli Esquerdo Lopes }\end{array}$ \\
\hline 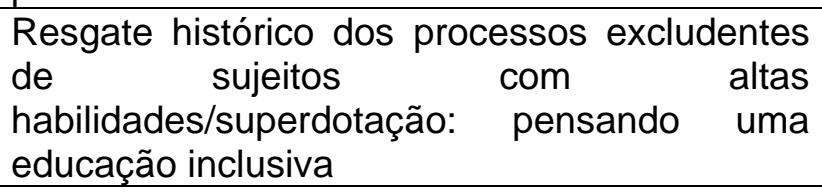 & $\begin{array}{l}\text { Miriam de Oliveira Maciel } \\
\text { Bárbara Martins de Lima Delpretto } \\
\text { Soraia Napoleão Freitas }\end{array}$ \\
\hline $\begin{array}{l}\text { Lembranças de vida: a voz de uma pessoa com } \\
\text { deficiência }\end{array}$ & $\begin{array}{l}\text { Gabriela Ruiz Berribille } \\
\text { Kátia Regina Moreno Caiado }\end{array}$ \\
\hline $\begin{array}{l}\text { Políticas para educação especial pós 1994: um } \\
\text { estudo sobre o conceito de surdez }\end{array}$ & Raquel Elizabeth Saes Quiles \\
\hline $\begin{array}{l}\text { As relações institucionais e a criança } \\
\text { transtornada }\end{array}$ & $\begin{array}{l}\text { Emilene Coco dos Santos } \\
\text { Emilia Helena da Silva Frizzera }\end{array}$ \\
\hline $\begin{array}{l}\text { A deficiência como condição de vulnerabilidade } \\
\text { social: aplicações da teoria da resiliência à luz } \\
\text { da história de vida de mulheres com deficiência }\end{array}$ & $\begin{array}{l}\text { Adenize Queiroz de Farias } \\
\text { Profa. Dra. Windyz B. Ferreira }\end{array}$ \\
\hline \multicolumn{2}{|l|}{2012} \\
\hline $\begin{array}{l}\text { História de vida de atletas participantes do } \\
\text { handebol em cadeira de rodas }\end{array}$ & $\begin{array}{l}\text { Caroline Anne Duarte; Francieli de } \\
\text { Abreu; Nicoli Alves; Robson Frank; } \\
\text { Douglas Borella }\end{array}$ \\
\hline
\end{tabular}




\begin{tabular}{|c|c|}
\hline $\begin{array}{l}\text { A escola especial como marco inicial do } \\
\text { atendimento educacional especializado no } \\
\text { município de Cornélio Procópio, Estado do } \\
\text { Paraná }\end{array}$ & $\begin{array}{l}\text { Patrícia Padilha Porto; Esther Lopes } \\
\text { Maria Cristina Marquezine; Viviane } \\
\text { Tramontina Leonessa }\end{array}$ \\
\hline $\begin{array}{l}\text { A inclusão de alunos com deficiência na } \\
\text { educação básica: entendendo o contexto } \\
\text { histórico para valorizar práticas pedagógicas } \\
\text { atuais }\end{array}$ & $\begin{array}{l}\text { Camila Reis dos Santos; Michell } \\
\text { Pedruzzi Mendes Araújo e Vanessa } \\
\text { Pita Barreira Burgos Manga }\end{array}$ \\
\hline $\begin{array}{l}\text { Trajetória histórica dos cursos de Pedagogia da } \\
\text { Universidade Estadual Paulista "Júlio de } \\
\text { Mesquita Filho". }\end{array}$ & $\begin{array}{l}\text { Cristiane Regina Xavier Fonseca- } \\
\text { Janes }\end{array}$ \\
\hline $\begin{array}{l}\text { A educação especial e a deficiência nos } \\
\text { pressupostos de Vigotski: análise da resolução } \\
\text { do comitê central do partido comunista da } \\
\text { Rússia de } 04 \text { de julho de } 1936\end{array}$ & $\begin{array}{l}\text { Otávio Augusto de Moraes; Tiago } \\
\text { Ribeiro dos Anjos; Daniele Lozano; } \\
\text { Fernanda Vilhena Mafra Bazon }\end{array}$ \\
\hline $\begin{array}{l}\text { Resgate histórico da evolução do atendimento } \\
\text { educacional a alunos com deficiência visual }\end{array}$ & $\begin{array}{l}\text { Josefa Lídia Costa Pereira ; Mari } \\
\text { Piedade Resende da Costa; Sa } \\
\text { Regina Costa Pereira }\end{array}$ \\
\hline $\begin{array}{l}\text { A importância da língua de sinais na formação } \\
\text { da pessoa surda }\end{array}$ & Aline Cleide Batista \\
\hline $\begin{array}{l}\text { Inteligência e deficiência intelectual: } \\
\text { considerações sobre a psicometria de Binet e } \\
\text { Simon e a defectologia de Vygotski }\end{array}$ & $\begin{array}{l}\text { Sonia Mari Shima Barroco; Fernanda } \\
\text { Santos de Castro }\end{array}$ \\
\hline $\begin{array}{l}\text { Formação de professores e inclusão: políticas } \\
\text { públicas no Brasil entre } 1988 \text { E } 2010\end{array}$ & $\begin{array}{l}\text { Lana Ferreira de Lima: Virgínio Isidro } \\
\text { Martins Sá }\end{array}$ \\
\hline gos e seus ledores: histórias, & Adriany Thatcher Castro Soares \\
\hline $\begin{array}{l}\text { líticas de inclusão no contexto } \\
\text { ta: um olhar (auto)biográfico }\end{array}$ & Márcia Moreira da Silva \\
\hline \multicolumn{2}{|l|}{2014} \\
\hline $\begin{array}{l}\text { Inclusão: conhecendo um pouco da } \\
\text { história/educação de sujeitos surdos }\end{array}$ & $\begin{array}{l}\text { Dulcéria Tartuci; Wellington Jhonner } \\
\text { Divino Barbosa da Silva }\end{array}$ \\
\hline $\begin{array}{l}\text { A deficiência intelectual na vida adulta: uma } \\
\text { história de vida }\end{array}$ & $\begin{array}{l}\text { Rosangela Cristina Sales Tezori; } \\
\text { Fátima Elisabeth Denari }\end{array}$ \\
\hline $\begin{array}{l}\text { Significações na história de vida de uma } \\
\text { pessoa cega: implicações e enfrentamentos }\end{array}$ & $\begin{array}{l}\text { Mariane Carloto da Silva; Amanda de } \\
\text { Cassia Borges; Josefa Lídia Costa } \\
\text { Pereira }\end{array}$ \\
\hline $\begin{array}{l}\text { Professores com deficiência no município de } \\
\text { Vitória: formação profissional e relatos de } \\
\text { histórias de vida }\end{array}$ & $\begin{array}{l}\text { Camila Reis dos Santos; Rogério } \\
\text { Drago }\end{array}$ \\
\hline $\begin{array}{l}\text { A trajetória da Libras na comunidade surda do } \\
\text { município de Guanambi }\end{array}$ & $\begin{array}{lll}\text { Joilce Karine } & \text { Fernandes } & \text { Silva } \\
\text { Pereira; Kátia Montalvão } & \\
\end{array}$ \\
\hline $\begin{array}{l}\text { A concepção de criança na história dos } \\
\text { transtornos do desenvolvimento na infância }\end{array}$ & Mariane Falco e Tizuko M. Kishimoto \\
\hline $\begin{array}{l}\text { Histórias escolares de surdos em Rio Bonito: } \\
\text { entre o Maior e o menor da educação }\end{array}$ & $\begin{array}{l}\text { Luma Balbi de Figueiredo e Cordeiro } \\
\text {; } \\
\text { Márcia da Silva Freitas }\end{array}$ \\
\hline $\begin{array}{l}\text { Fragmentos da História dos Primeiros Anos da } \\
\text { Política de Educação Especial no Distrito } \\
\text { Federal }\end{array}$ & $\begin{array}{l}\text { Patrícia Augusta Ferreira Vilas Boas; } \\
\text { Amaralina Miranda de Souza }\end{array}$ \\
\hline
\end{tabular}




\begin{tabular}{|c|c|}
\hline $\begin{array}{l}\text { Normalidade, diversidade e alteridade na } \\
\text { história da unidade de educação especial } \\
\text { "Professor Astério de Campos" }\end{array}$ & $\begin{array}{l}\text { José Anchieta de Oliveira Bentes; } \\
\text { Rita de Nazareth Souza Bentes }\end{array}$ \\
\hline \multicolumn{2}{|l|}{2016} \\
\hline $\begin{array}{l}\text { Uma história especial marcada por uma vida à } \\
\text { educação especial }\end{array}$ & $\begin{array}{l}\text { Dulcilene R. Barreto; Márcia Cruz; } \\
\text { Miriam Adalgisa Bedim Godoy; Rita } \\
\text { de Cássia Gomes de Oliveira } \\
\text { Almeida }\end{array}$ \\
\hline $\begin{array}{l}\text { Organização e Trabalho docente de } \\
\text { professores surdos no ensino de Libras: das } \\
\text { políticas às práticas }\end{array}$ & $\begin{array}{l}\text { Stela Cabral de Andrade ; Ernani } \\
\text { Coimbra de Oliveira; Isabel Cristina } \\
\text { Adão; Beatriz Diniz }\end{array}$ \\
\hline $\begin{array}{l}\text { A organização das pessoas com deficiência: } \\
\text { participação na Assembleia Nacional } \\
\text { Constituinte, } 1987-1988 \text { e suas reivindicações }\end{array}$ & Joyce Fernanda Guilanda de Amorim \\
\hline $\begin{array}{l}\text { Breve história do ensino ajustado à percepção } \\
\text { tátil }\end{array}$ & $\begin{array}{l}\text { Louise Costa da Silvia Almeida; } \\
\text { Patrícia de Cássia Pereira Porto; } \\
\text { Alcindo Miguel Martins Filho; Priscila } \\
\text { Tamiasso-Martinhon e Célia Sousa }\end{array}$ \\
\hline $\begin{array}{l}\text { Análise da produção acadêmica e científica da } \\
\text { professora Dra Eniceia Gonçalves Mendes por } \\
\text { meio da história de vida }\end{array}$ & $\begin{array}{l}\text { Patricia Zutião; Rossicleide Santos } \\
\text { da Silva; Augusto Marques Alves ; } \\
\text { Helen Cristiane Viana Alves; Mariana } \\
\text { Moraes Lopes }\end{array}$ \\
\hline $\begin{array}{l}\text { Inclusão x Exclusão: Histórico, Políticas e } \\
\text { Práticas do Processo Inclusivo }\end{array}$ & Marisa Mendes Machado de Souza \\
\hline $\begin{array}{l}\text { O projeto da Ditadura Militar para a Educação } \\
\text { Especial nos territórios federais: } 1964 \text { a } 1985\end{array}$ & Maria Edith Romano Siems \\
\hline $\begin{array}{l}\text { Síntese da trajetória do Grupo de Voluntários, } \\
\text { Copistas e Ledores para Cegos - GVCLC }\end{array}$ & Robenilson Nascimento dos Santos \\
\hline $\begin{array}{l}\text { Uma análise da produção recente acerca da } \\
\text { história da educação especial no Brasil }\end{array}$ & $\begin{array}{l}\text { Keisyani da Silva Santos; Enicéia } \\
\text { Gonçalves Mendes }\end{array}$ \\
\hline $\begin{array}{l}\text { Helena Antipoff e os trabalhos voltados para } \\
\text { educação e formação de pessoas no Brasil }\end{array}$ & $\begin{array}{l}\text { Laressa Rodrigues Rocha; Dulcéria } \\
\text { Tartuci }\end{array}$ \\
\hline $\begin{array}{l}\text { Os desafios da educação inclusiva na } \\
\text { sociedade capitalista: considerações sobre as } \\
\text { pessoas com necessidades especiais }\end{array}$ & $\begin{array}{l}\text { Luana Aparecida de Oliveira; Luís } \\
\text { Fernando Jacques; Gelssi Ferreira }\end{array}$ \\
\hline $\begin{array}{l}\text { A educação especial no município de Maceió: } \\
\text { das Classes Especiais às Salas de Recursos } \\
\text { Multifuncionais }\end{array}$ & $\begin{array}{l}\text { Elisangela Leal de Oliveira Mercado; } \\
\text { Neiza de Lourdes Frederico Fumes }\end{array}$ \\
\hline $\begin{array}{l}\text { Políticas de educação especial no Brasil e a } \\
\text { educação de Surdos em Breves - Pará }\end{array}$ & Huber Kline Guedes Lobato \\
\hline $\begin{array}{l}\text { Ressignificando as clínicas de condução infantil } \\
\text { sob a perspectiva de Alfred Adler }\end{array}$ & Daniela Leal \\
\hline $\begin{array}{l}\text { Aspectos históricos da introdução da } \\
\text { psicometria no Brasil }\end{array}$ & $\begin{array}{l}\text { Carla Mercês da Rocha Jatobá } \\
\text { Ferreira }\end{array}$ \\
\hline $\begin{array}{l}\text { A escolarização de surdos e cegos no Brasil e } \\
\text { na França: os primeiros institutos de educação } \\
\text { especializada }\end{array}$ & $\begin{array}{l}\text { Roberta Baessa Estimado; Cássia } \\
\text { Geciauskas Sofiato }\end{array}$ \\
\hline $\begin{array}{l}\text { Participação social: conselhos de direitos e a } \\
\text { composição do conselho nacional das pessoas } \\
\text { com deficiências- CONADE }\end{array}$ & Lourdes do Nascimento Duarte \\
\hline
\end{tabular}




\begin{tabular}{|c|c|}
\hline $\begin{array}{l}\text { A história da educação especial de um } \\
\text { município do interior da Bahia: AEE em foco }\end{array}$ & $\begin{array}{l}\text { Camila de Moura Costa; Maria } \\
\text { Orlândia de Melo Belmiro; Mey de } \\
\text { Abreu van Munster }\end{array}$ \\
\hline $\begin{array}{l}\text { A história de educação especial/inclusiva: } \\
\text { desvelando os conceitos de in/exclusão, } \\
\text { biopolítica e governabilidade } \\
\text { O processo histórico de inserção social da } \\
\text { pessoa cega na Antiguidade }\end{array}$ & $\begin{array}{l}\text { Marciane Cosmo; Hiran Pinel; } \\
\text { Cleyton Santana de Sousa; } \\
\text { Leonardo Barth; Jaqueline Bragio } \\
\text { Ailton Barcelos da Costa ; } \\
\text { Alessandra D. M. Picharillo; Vanessa } \\
\text { Cristina Paulino }\end{array}$ \\
\hline $\begin{array}{l}\text { Entre a norma e a experiência: o ensino da } \\
\text { disciplina "mathematicas, geographia e história } \\
\text { do Brasil" no Imperial Instituto dos Surdos- } \\
\text { Mudos }\end{array}$ & $\begin{array}{l}\text { Daniella Cristina Bosco; Cássia } \\
\text { Geciauskas Sofiato }\end{array}$ \\
\hline $\begin{array}{l}\text { A influência de Helen } \\
\text { especial brasileira: ent }\end{array}$ & $\begin{array}{l}\text { Adriana Araújo Pereira Borges; } \\
\text { Regina Helena de Freitas Campos }\end{array}$ \\
\hline & \\
\hline $\begin{array}{l}\text { Educação especial e educação inclusiva: } \\
\text { alguns apontamentos históricos e legais }\end{array}$ & $\begin{array}{l}\text { Ana Mara Coelho da Silva; Marcelo } \\
\text { Marques de Araújo }\end{array}$ \\
\hline $\begin{array}{l}\text { Método Oral: Análise dos Diários de Classe do } \\
\text { Curso de Especialização no Instituto Nacional } \\
\text { de Educação de Surdos (1960-1961) }\end{array}$ & $\begin{array}{l}\text { Catharine Prata Seixas; Verônica dos } \\
\text { Reis Mariano Souza; Jorge Carvalho } \\
\text { do Nascimento }\end{array}$ \\
\hline $\begin{array}{l}\text { Oralismo: os livros traduzidos no Instituto } \\
\text { Nacional de Educação de Surdos (1951-1961) }\end{array}$ & $\begin{array}{l}\text { Catharine Prata Seixas ; Alessandra } \\
\text { Santana Soares Barros; Theresinha } \\
\text { Guimarães Miranda }\end{array}$ \\
\hline $\begin{array}{l}\text { Histórias sobre o papel das instituições } \\
\text { especializadas de cunho filantrópico em jornal } \\
\text { impresso }\end{array}$ & $\begin{array}{l}\text { Keisyani da Silva Santos; Enicéia } \\
\text { Gonçalves Mendes }\end{array}$ \\
\hline $\begin{array}{l}\text { Educação inclusiva e direitos humanos: } \\
\text { recortes das tensões e resistências existentes } \\
\text { no contexto brasileiro }\end{array}$ & Nelma Alves Marques Pintor \\
\hline $\begin{array}{l}\text { ia da educação inclusiva na perspectiva } \\
\text { sses Hospitalares. }\end{array}$ & Tyara Carvalho de Oliveira \\
\hline $\begin{array}{l}\text { da educação especial no município de } \\
\text { dos }\end{array}$ & Vanêssa Lima do Nascimento \\
\hline $\begin{array}{l}\text { Exclusão, segregação e Inclusão: a história da } \\
\text { educação especial/inclusiva dos deficientes } \\
\text { visuais }\end{array}$ & Diones Carlos de Souza Almeida \\
\hline $\begin{array}{l}\text { Resgatando o passado: a importância da } \\
\text { Escola para Cegos "Helen Keller" de Ribeirão } \\
\text { Preto (1954-1990) }\end{array}$ & Daniela Leal \\
\hline Pérolas do Elyseu - 30 anos produzindo jóias & $\begin{array}{l}\text { Marco Aurélio Freire Ferraz; Sandra } \\
\text { Elisabete Porto da Silva }\end{array}$ \\
\hline $\begin{array}{l}\text { A abordagem da educação especial nas } \\
\text { conferências internacionais de educação } \\
(1934-1963)\end{array}$ & $\begin{array}{l}\text { Fernanda Luísa de Miranda Cardoso; } \\
\text { Silvia Alicia Martinez }\end{array}$ \\
\hline $\begin{array}{l}\text { Normas da educação especial mineira: da fase } \\
\text { excludente à inclusão }\end{array}$ & $\begin{array}{l}\text { Adriana Araújo Pereira Borges; Paulo } \\
\text { Vitor Rodrigues da Silva; IImer } \\
\text { Maciel Oliveira }\end{array}$ \\
\hline $\begin{array}{l}\text { Educação especial brasileira: antecedentes à } \\
\text { criação do CENESP (1950 A 1973) }\end{array}$ & $\begin{array}{l}\text { Getsemane de Freitas Batista; Carla } \\
\text { de Paiva; Izadora Martins da Silva de } \\
\text { Souza }\end{array}$ \\
\hline
\end{tabular}




\begin{tabular}{|c|c|}
\hline $\begin{array}{l}\text { História de uma escola inclusiva na Baixada } \\
\text { Fluminense/RJ }\end{array}$ & Leila Lopes de Avila \\
\hline $\begin{array}{l}\text { O atendimento escolar hospitalar faz parte da } \\
\text { educação especial? }\end{array}$ & $\begin{array}{l}\text { Camila Camilozi Alves Costa de } \\
\text { Albuquerque Araújo; Eneida Simões } \\
\text { da Fonseca }\end{array}$ \\
\hline $\begin{array}{l}\text { "Do entorno ao chão da escola": (re) pensar a } \\
\text { estrutura da educação especial em Sergipe a } \\
\text { partir da missão cubana (1996 a 1998) }\end{array}$ & $\begin{array}{l}\text { Cândida Luísa Pinto Cruz; Patrícia } \\
\text { Matos Souza Nunes; Rita de Cácia } \\
\text { Santos Souza }\end{array}$ \\
\hline \multicolumn{2}{|l|}{ CIHELA } \\
\hline \multicolumn{2}{|l|}{2014} \\
\hline $\begin{array}{l}\text { Educação Física e Representações da Criança } \\
\text { Deficiente: Uma Mirada a partir do Colégio Brasileiro } \\
\text { de Ciências do Esporte (1978-1999 }\end{array}$ & Cristina Borges de Oliveira \\
\hline $\begin{array}{l}\text { Relação Entre o Instituto de Cegos da Bahia (ICB) e } \\
\text { as Primeiras Iniciativas do Poder Público de Acesso } \\
\text { à Escola Regular dos Estudantes com Deficiência } \\
\text { Visual (1937-1964) }\end{array}$ & Raimundo. Nonato Santos \\
\hline $\begin{array}{l}\text { Se podes ver. A Educação de Crianças Cegas e de } \\
\text { Baixa Visão sob a Batuta da Professora Maria } \\
\text { Terezinha de Carvalho }\end{array}$ & Leila Blanco Rocha Varela \\
\hline $\begin{array}{l}\text { Políticas Públicas Educacionais para Pessoas com } \\
\text { Deficiência no Brasil e os Organismos } \\
\text { Internacionais: Influências na Trajetória da } \\
\text { Educação Inclusiva }\end{array}$ & $\begin{array}{l}\text { Leonor Paniago Rocha; } \\
\text { Márcio Mota de Castro }\end{array}$ \\
\hline \multicolumn{2}{|l|}{2016} \\
\hline $\begin{array}{l}\text { A Educação de Crianças no Hospital de Crianças de } \\
\text { Curitiba, 1956-1988 }\end{array}$ & Claudinéia Maria Vischi Avanzini \\
\hline $\begin{array}{l}\text { Maria Therezinha de Carvalho Machado na } \\
\text { Educação Especial Pública da Cidade do Rio de } \\
\text { Janeiro }\end{array}$ & Leila Blanco \\
\hline \multicolumn{2}{|l|}{2018} \\
\hline $\begin{array}{l}\text { A educação da criança com deficiência intelectuall } \\
\text { na fundação Pestalozzi do Pará (1953-1963): Uma } \\
\text { análise discursiva }\end{array}$ & $\begin{array}{l}\text { Cibele Braga Ferreira Nascimento; Laura } \\
\text { Maria Araújo }\end{array}$ \\
\hline $\begin{array}{l}\text { A História da Educação de Crianças em Hospitais: } \\
\text { A Experiência nos Países Ocidentais, } 1889-2005\end{array}$ & Claudinéia Maria Vischi Avanzini \\
\hline $\begin{array}{l}\text { Outras Histórias: A Cultura Escolar de um } \\
\text { Educandário para Cegos no Interior do Estado do } \\
\text { Rio de Janeiro }\end{array}$ & $\begin{array}{l}\text { Fernanda Luísa de Miranda Cardoso e ; } \\
\text { Silvia Alícia Martínez }\end{array}$ \\
\hline $\begin{array}{l}\text { O Livro Acessível a Cegos e Surdos e as Políticas } \\
\text { Públicas Brasileiras }\end{array}$ & Tatiana de Andrade Fulas \\
\hline $\begin{array}{l}\text { Trajetória de Formação Docente: } \\
\text { Cegas do Professoras } \\
\text { Fundamental do Instituto Begmento do Ensino } \\
\text { Fumin Constant }\end{array}$ & $\begin{array}{l}\text { Márcia de Lourdes Carvalho de Oliveira.; } \\
\text { Nailda Marinho da Costa }\end{array}$ \\
\hline $\begin{array}{l}\text { Filantropia e Educação Especial: Perspectivas em } \\
\text { Disputa na Amazônia Brasileira Entre as Décadas } \\
\text { de } 1980 \text { e } 1990\end{array}$ & Maria Edith Romano Siems-Marcondes \\
\hline 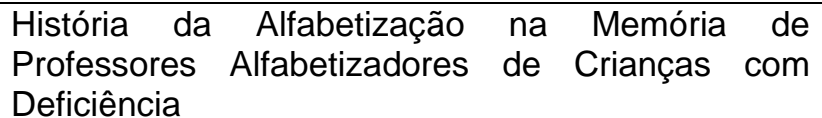 & $\begin{array}{l}\text { Jefferson Lack da Silva e Estela Natalina } \\
\text { Mantovani Bertoletti }\end{array}$ \\
\hline
\end{tabular}




\section{Correspondência}

Adriana Araújo Pereira Borges - Universidade Federal de Minas Gerais, Faculdade de Educação, Avenida Antônio Carlos, 6627, Campus Pampulha, Belo Horizonte, Minas Gerais - Brasil.

CEP: $31270-901$

\section{(c) (i) (8)} 4.0 International (CC BY-NC 4.0) 